\title{
Turbidity triggers larval release by the intertidal barnacle Semibalanus balanoides
}

\author{
Joanna Gyory ${ }^{1,2, *}$, Jesús Pineda ${ }^{1}$, Andrew Solow ${ }^{3}$ \\ ${ }^{1}$ Biology Department, Woods Hole Oceanographic Institution, Woods Hole, MA 02543 \\ ${ }^{2}$ Center for Marine and Environmental Studies, University of the Virgin Islands, St. \\ Thomas, VI 00802 \\ ${ }^{3}$ Marine Policy Center, Woods Hole Oceanographic Institution, Woods Hole, MA 02543
}

\section{ABSTRACT:}

Gravid adults of the common intertidal barnacle Semibalanus balanoides (L.) brood fully developed larvae until individuals perceive some cue from the environment that triggers synchronous larval release. The prevailing hypothesis has been that phytoplankton blooms trigger release because they provide a food source for nauplius larvae. Through observations and field experiments, we tested the hypothesis that turbidity from any source, not just phytoplankton blooms, can trigger release. We documented five larval release events at three sites in the northeastern United States. Two events coincided with chlorophyll increases, and all five coincided with turbidity increases. In experiments, the larval release response was equivalent when adults were exposed to diatoms or inert synthetic beads, and it was significantly higher than under exposure to filtered seawater. We also tested the hypothesis that turbidity can decrease the risk of cannibalism for newly-released nauplii. Under experimentally manipulated conditions, adults consumed significantly fewer nauplii in a high-turbidity environment. We suggest that reproduction in this species may have evolved to coincide roughly with the local onset of winter/spring phytoplankton blooms, but the timing of larval release may have been fine-tuned further 
27 by cannibalism and predation pressures. The potential for turbid conditions to serve as a

28 refuge for planktonic larvae of other marine organisms merits further investigation.

30 KEY WORDS:

31 Synchrony $\cdot$ Turbidity $\cdot$ Reproduction $\cdot$ Larvae $\cdot$ Cannibalism $\cdot$ Barnacles

32

$34 *$ Email: jgyory@uvi.edu

\section{INTRODUCTION}

The plankton community in coastal waters of the temperate North Atlantic Ocean

40 changes considerably with the seasons. In late winter or early spring, dense diatom

41 blooms appear, and they are often followed shortly after by pelagic nauplius larvae of the

42 common and widespread intertidal barnacle Semibalanus balanoides (Fish 1925). In

43 some areas, S. balanoides larvae account for up to $15 \%$ of zooplankton individuals

44 (Frolander 1955), but remain in the water column for only 3-6 weeks (Barnes and Barnes

45 1958). Nauplii feed on phytoplankton and are themselves prey for carnivorous

46 zooplankton and planktivorous fish (Lockhead 1936; Bousfield 1955). Therefore, the

47 timing of S. balanoides larval release relative to the seasonal population dynamics of

48 other species could have an important effect on coastal marine food webs. 
50 the developmental sequence is complete until individuals encounter environmental

51 conditions that prompt larval release in mass synchrony (Moore 1935; Barnes 1962). The

52 synchronous release of nauplii often coincides with phytoplankton blooms (Barnes 1956,

53 1957, 1962), presumably to ensure a plentiful food supply for the larvae. However, in the

54 field, larvae are sometimes released in the absence of diatom blooms (Barnes 1962), and

55 adults in the laboratory often release when exposed to high concentrations of many kinds

56 of plankton, including brine shrimp nauplii (Starr et al. 1991). Additionally, we (Gyory

57 and Pineda 2011) found that the abundance of first-stage nauplii was strongly correlated

58 with the passage of storms that increased water turbidity. We therefore suggested that

59 larval release may be triggered by high turbidity (caused by phytoplankton blooms or

60 other sources) because the weakly-swimming, newly-released larvae are better protected

61 from cannibalism when the filter-feeding appendages of adults are temporally clogged by

62 particles; the "turbidity hypothesis."

63 In the present study, we tested three predictions of the turbidity hypothesis: (1)

64 Larval release in the field should coincide with periods of high phytoplankton abundance

65 or high turbidity from other sources. (2) Adult barnacles should release larvae when

66 exposed to high concentrations of phytoplankton or inert synthetic beads. (3) High

67 turbidity should decrease the rate of cannibalism on newly-released barnacle larvae.

68

69 MATERIAL AND METHODS

71 Field observations of larval release patterns 
73 We tracked the larval release patterns of barnacles at three sites along the

74 northeastern coast of the United States to determine whether release was related to

75 changes in turbidity, chlorophyll concentration, or various abiotic variables (water

76 temperature, salinity, or depth). The three field sites were (1) a dock in Little Harbor,

77 Woods Hole, Massachusetts (4131.366’ N, 70 40.008’ W); (2) the University of Rhode

78 Island pier in Narragansett, Rhode Island (41 $\left.29.524^{\prime} \mathrm{N}, 7^{\circ} 25.145^{\prime} \mathrm{W}\right)$; and (3) the

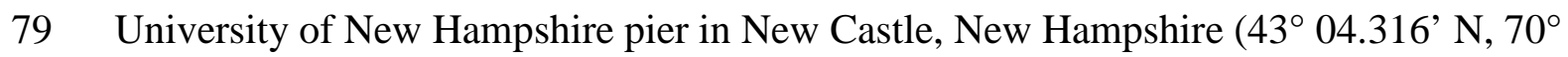

$8042.707^{\prime}$ W) (Fig. 1). Larval release of Semibalanus balanoides is known to occur

81 sequentially, in this order, in these three regions (Fish 1925; Pineda et al. unpub.). All

82 sites had an abundance of $S$. balanoides adults distributed vertically in the intertidal zone

83 from approximately high water to low water spring tide levels, which is the usual range

84 for this species (Stubbings 1975).

85 From November 21, 2009 to February 25, 2010, we sampled barnacle adults to

86 determine what proportion of the population was gravid and what proportion had empty

87 mantle cavities. When a Semibalanus balanoides individual releases its larvae, all larvae

88 leave the mantle cavity, usually in 24 hours or less (Barnes 1955). Thus, a rapid increase

89 in the proportion of adults with empty mantle cavities signaled a larval release event. We

90 randomly sampled at least 31 adult barnacles (mean $=60, \mathrm{SD}=19$ ) daily whenever

91 possible. On a few occasions, severe weather impeded sampling efforts.

92 At the three field sites, we measured water salinity, temperature, depth, turbidity,

93 and chlorophyll fluorescence. A logger (model XR-420, RBR Ltd., Ottawa, Ontario,

94 Canada) recorded temperature and salinity every five minutes. A fluorometer (dual- 
95 wavelength, single-angle sensor) measured turbidity and in vivo chlorophyll fluorescence

96 simultaneously (model ECO FLNTU, WET Labs, Philomath, Oregon, USA). The

97 instrument took a "burst" of measurements (one per second for five seconds) every five

98 minutes. In Massachusetts and Rhode Island, we strapped the instruments to pier pilings

$99 \quad 0.5 \mathrm{~m}$ above bottom. The water depth was $1.5-2 \mathrm{~m}$ during the highest tides. In New

100 Hampshire, it was not possible to strap the instruments to pier pilings, so the instruments

101 were attached to a floating dock instead, where they remained $0.5 \mathrm{~m}$ below the surface at

102 all times. We obtained tide and water level data from the United States National Oceanic

103 and Atmospheric Administration (station ID numbers: 8447930, 8452660, and 8423898).

104 Instrumentation problems at the Massachusetts site caused loss of salinity data

105 and required that we eliminate some bad values from the turbidity and chlorophyll data.

106 A piece of macroalga wrapped itself around the ECO fluorometer, and every time the

107 blades of the alga swept past the sensors, the readings were unrealistically high. We

108 removed the bad values from the chlorophyll and turbidity data (in Massachusetts only)

109 as follows: (1) Since the instrument sampled once per second for 5 seconds every 5

110 minutes, we computed the median for each 5-second sampling burst. This eliminated bad

111 data in situations when only some of the values in the sampling burst were affected by the

112 alga. (2) When all five values in a sampling burst were bad, we divided the sampling

113 period into 2-hour bins and calculated the mean and standard deviation of the values in

114 the bins. If the standard deviation of the mean was equal to or greater than half of the

115 mean, we eliminated the highest 1/3 of the values from the 2-hour bin. (3) We calculated

116 the median values for each 1-hour bin, and those are the values used in the analyses (see 
117 Electronic Supplement 1 for figures of filtered and un-filtered data). After these

118 corrections, the effective sampling rate for the instrument became $1 \mathrm{hr}^{-1}$.

120 Larval release in response to phytoplankton or turbidity

We conducted experiments to test whether the larval release response was

123 different when gravid adult barnacles were exposed to unfiltered seawater, seawater with

124 diatoms added, or seawater with particles added. The diatom was Skeletonema marinoi

125 Sarno et Zingone (strain CCMP 1332 from the National Marine Phytoplankton Collection

126 [NMPC] at Bigelow Laboratory for Ocean Sciences) added at $10^{7}$ cells $\mathrm{L}^{-1}$. Although

127 many previous studies on barnacle feeding reported using the diatom Skeletonema

128 costatum (Greville) Cleve, a recent study discovered that $S$. costatum is actually a species

129 complex made up of previously unrecognized species, including S. marinoi (Sarno et al.

130 2005). The strain we used from the NMPC had been identified initially as S. costatum

131 when it was collected in 1956, but has been re-classified since then. It has a cell length of

132 6-14 $\mu \mathrm{m}$, cell width of 6-8 $\mu \mathrm{m}$, and forms chains of 2-45 cells. The particles we used

133 were neutrally-buoyant Dynoseeds ${ }^{\circledR}$ 40- $\mu$ m polystyrene beads (Microbeads AS,

134 Skedsmokorset, Norway) added at $10^{7}$ beads $\mathrm{L}^{-1}$.

135 At each field site during low tide, we gathered barnacle-covered rocks that were

136 small enough to fit inside a one-liter clear plastic jar. We placed one rock inside each jar

137 and immediately filled it with one of the three treatments listed above. After sealing the

138 jars with lids, we placed them inside plastic cages that floated at the water surface and

139 were tethered to the sampling dock. We assume that the floating cages maintained the 
140 jars at ambient water temperature and ambient light levels, and the slight to moderate

141 wave action around the docks kept the phytoplankton and beads suspended inside the jars.

142 After 24 hours, we recovered the jars, filtered the water through $100 \mu \mathrm{m}$ mesh, and

143 counted the number of nauplii swimming in the water and the number of adults on each

144 rock. We ran experiments twice in Rhode Island and twice in New Hampshire.

145 Experiments contained multiple replicates of each treatment (Table 1).

146 The statistical analysis for these experiments tested the null hypothesis that there

147 is no difference in the larval release response of adults when exposed to beads,

148 Skeletonema marinoi, or unfiltered seawater, versus the alternative hypothesis that there

149 is a difference among the three treatments. There were two complicating factors. First,

150 not all the adults were gravid at the beginning of the experiments, and it was impossible

151 to determine how many were gravid without sacrificing the animals. Second, the number

152 of nauplii produced can be highly variable among individuals. To address these

153 uncertainties, we developed a statistical model relating the observed number of nauplii in

154 each jar to the unknown number of gravid adults and the distribution of the number of

155 nauplii released by each of them. Based on this model, we performed a likelihood ratio

156 test of the null hypothesis that the conditional mean number of nauplii released by an

157 adult was the same for the three experimental treatments (see Electronic Supplement 2

158 for details). We repeated the entire analysis while omitting the outlier from the S. marinoi

159 treatment (see Results) because the outlier could have undue influence on the results.

160 We considered the possibility that the number of nauplii that we found in the jars

161 at the end of each experiment could differ among treatments if the rates of cannibalism

162 by adults were also different among treatments. Thus, in addition to comparing the 
163 number of nauplii in the jars, we also examined the percentage of treatment replicates in

164 which adults were inferred to have participated in "mass release” (defined as 95\% or

165 more of adults in a jar with empty mantle cavities). Mass release could only be inferred,

166 not verified, because it was impossible to determine whether adults were gravid at the

167 beginning of the experiment without sacrificing them.

Predation rate of adults on newly released larvae under normal or turbid conditions

171 We tested the null hypothesis that turbidity would not affect the rate of

172 cannibalism on newly-released barnacle larvae by exposing adults either to larvae and

173 synthetic beads or to larvae alone. The experiment took place in New Hampshire on

174 February 19, 2010. By this date, most (>75\%) of the barnacles we sampled in the field

175 had already released their larvae, so we assumed that the adults in the experiments also 176 had released their larvae.

177 The experiment consisted of 5 jars with a control treatment (seawater filtered 178 through $100 \mu \mathrm{m}$ mesh) and 5 jars with an experimental treatment (filtered seawater with $17940 \mu \mathrm{m}$ Dynoseeds ${ }^{\circledR}$ added at $10^{7}$ beads $\mathrm{L}^{-1}$ ). Each 1-L jar contained one rock covered 180 with barnacle adults. The number of adults in a jar was random, and not significantly 181 different among treatments. We added at least 250 live, actively swimming nauplii to 182 each jar, noting the exact number used. To obtain the nauplii, we scraped adults off pier 183 pilings along the uppermost limit of the barnacle colonies. A few $(<25 \%)$ of these adults

184 still had viable eggs inside their mantle cavities. We collected the eggs from 10

185 individuals and placed them in seawater (pre-filtered through $100 \mu \mathrm{m}$ mesh). The eggs 
186 hatched within minutes, and nauplii swam to the surface. Using a glass pipette, we

187 suctioned actively swimming larvae and added them to the experimental jars. We sealed

188 the jars with lids, placed them in the plastic cages described above, and hung the cages

189 off the pier so that the jars were submerged in seawater.

190 The experiment began at 14:00 and ended at 20:00. At the end of the experiment,

191 we filtered water from each jar through $100 \mu \mathrm{m}$ mesh and counted the number of nauplii

192 that remained. We calculated the percentage of nauplii that survived in each jar without

193 being consumed and performed a one-way ANOVA to detect any differences in the

194 means for the two treatments.

196 RESULTS

198 Field observations of larval release

200 There were five major larval release events at the three sites. Two of the events

201 coincided with higher chlorophyll levels, but all five coincided with higher turbidity

202 levels. Two release events occurred in Massachusetts, one between December 12 and

203 December 14, and the other between December 18 and December 22 (Fig. 2). On

204 December 8, the increase in percent of empty adults might suggest that there was a

205 release event, but that is unlikely because the next three samples had a lower percentage

206 of empty adults. These barnacles reproduce once per year (Barnes 1963), so it is not

207 possible for them to release larvae and become gravid again a few days later. Similarly,

208 the decrease in percentage of empty adults on December 17 and 24 is likely due to 
209 sample variability. The percentage of adult barnacles that were brooding viable larvae

210 generally increased until reaching a maximum on December 17. The two decreases in this

211 percentage coincided with the two larval release events.

212 Chlorophyll concentration fluctuated between approximately 0.6 and $3 \mu \mathrm{g} \mathrm{L}^{-1}$ in

213 Massachusetts (Fig. 2). A short-lived, modest increase in chlorophyll concentration

214 occurred during the second larval release event, but not during the first. Turbidity ranged

215 from approximately 0.8 to 6.5 Nephelometric Turbidity Units (NTU). NTUs measure the

216 amount of light scattered by particles. A high-turbidity event was ending when the

217 instrument was placed in the water, and another event followed it the next day. These two

218 events coincided with the first larval release event. A second high-turbidity event

219 coincided with the second larval release event. Water level relative to mean lower low

220 water fluctuated between -0.1 and $1.4 \mathrm{~m}$. Water temperature declined steadily from $11^{\circ}$ to $221 \quad 1.5^{\circ} \mathrm{C}$.

222 In Rhode Island, major larval release events occurred between January 9 and

223 January 10 and between January 11 and January 13 (Fig. 3). During the first release, there

224 was an increase in turbidity, but no noticeable increase in chlorophyll. During the second

225 release, there was one high-chlorophyll event and two high-turbidity events. The

226 percentage of adult barnacles brooding viable larvae decreased during the larval release

227 events. Water level fluctuated between -0.5 and $1.7 \mathrm{~m}$. Salinity and water temperature

228 fluctuated with a semi-diurnal period, so they were probably tidally influenced. Salinity

229 ranged from 30.4 to $31.8 \mathrm{psu}$. Water temperature ranged from $1.4^{\circ}$ to $3.9^{\circ} \mathrm{C}$. During the

230 evening of January 12, an extreme low tide caused the instruments to be briefly exposed 
231 to air, so chlorophyll, turbidity, salinity, and water temperature data are missing for that

232 period.

233 In New Hampshire, larval release occurred between February 12 and 15 (Fig. 4).

234 The percentage of adult barnacles brooding viable larvae increased until it reached a

235 maximum on January 29. The percentage remained high until the larval release event

236 began on February 12. Chlorophyll values were generally low. Turbidity was generally

237 higher near the beginning of the sampling period and then decreased, but there was an

238 increase at high tide during the larval release period. Turbidity, salinity, and water

239 temperature fluctuated semi-diurnally with the tides. Water level ranged from -0.7 to 3.5

$240 \mathrm{~m}$. Salinity ranged from 22.7 to $31.7 \mathrm{psu}$. Water temperature ranged from $0.7^{\circ}$ to $4.2^{\circ} \mathrm{C}$.

241 In general, salinity and temperature increased and decreased as the tide flowed and ebbed, 242 respectively.

244 Larval release in response to phytoplankton or turbidity

246 Larval release response was significantly stronger (Likelihood Ratio [LR] test, $p$

$247<<0.001)$ in the phytoplankton and turbidity treatments than in the control treatments,

248 even when the outlier in the Skeletonema marinoi treatment was removed (LR test, $p<<$

249 0.001). The difference in larval release response between the phytoplankton and turbidity

250 treatments was not significantly different (LR test, $p \approx 1$ ) (Fig. 5).

251 The statistical model estimates of $\pi$ (the probability that an adult is gravid and

252 receptive to a larval release cue) are shown as percentages in Table 2. The model

253 estimates of $\theta$ (the unknown shape parameter of the negative binomial distribution), along 
254 with the estimated mean number of nauplii released by each gravid adult, are shown in

255 Table 3.

256 Twenty-seven percent of replicates for the control treatment had mass larval

257 release. In contrast, forty-six percent and fifty-four percent of bead and diatom replicates, 258 respectively, had mass release (Fig. 6).

260 Predation rate of adults on newly released larvae under normal or turbid conditions

The mean percentage of nauplii that escaped predation in the turbidity treatment

263 (85.4) was significantly greater (ANOVA, $p=0.015$ ) than in the control treatment (64.7)

264 (Fig. 7)

265

266 DISCUSSION

267

Gravid Semibalanus balanoides barnacles brood their larvae until they perceive

269 some cue from the environment that triggers naupliar release. The generally accepted

270 hypothesis has been that barnacles release their larvae in response to phytoplankton

271 blooms because high concentrations of phytoplankton provide abundant food for nauplii.

272 In contrast, Gyory and Pineda (2011) proposed that high turbidity (which can be caused

273 by phytoplankton blooms, sediments re-suspended by storms, or other sources) triggers

274 the release of larvae, since a highly turbid environment may protect poorly-swimming,

275 newly-released larvae from cannibalism and predation. Our field observations and

276 experiments tested the predictions that (1) high phytoplankton concentrations or (2) high 
277 turbidity levels trigger larval release in S. balanoides. We found that larval release in the

278 field and in controlled experiments could be triggered by high-turbidity events in the

279 absence of phytoplankton blooms.

280 We observed five major larval release events at three sites along the northeastern

281 coast of the United States. Two events coincided with increased chlorophyll

282 concentrations, three did not, but all five events coincided with increased turbidity. Other

283 authors have also noted that Semibalanus balanoides sometimes releases larvae in the

284 field in the absence of phytoplankton blooms. Barnes (1962) identified 2 years (1950 and

285 1960) in which larval release in Millport, Scotland occurred in the absence of blooms.

286 Another barnacle species, Chamaesipho brunnea, has been observed to release larvae

287 under conditions when turbidity would be expected to be high. In New Zealand, they

288 brood mature larvae during neap tides and calm weather, and release them during spring

289 tides and stormy weather (Foster 1965 as cited in Luckens 1970).

290 In Massachusetts, the two larval release events coincided with an increase in

291 turbidity. There was a small increase in chlorophyll during the second event, but not

292 during the first. Since macroalgal interference with our instrument sensors required

293 eliminating bad values from the data, it is possible that we failed to detect short-lived

294 pulses in chlorophyll. This is unlikely, though, because we were able to detect short-lived

295 pulses in turbidity after filtering the data, so we should have been able to do the same

296 with chlorophyll. There is an increase in the percentage of adults with no embryos from

$29735 \%$ on December 18 to 51\% on December 19 with seemingly no corresponding increase

298 in chlorophyll or turbidity. The data filtering process may have obscured an increase in 
299 one or both of these variables. In Rhode Island, there were increases in both turbidity and

300 chlorophyll at the second larval release event, but not during the first.

301 In New Hampshire, there was an increase in turbidity at the time of larval release,

302 but there was no major increase in chlorophyll. 92\% of adults were brooding viable

303 larvae during the highest turbidity event of the time series, on January 29. Why did the

304 barnacles fail to release during the high-turbidity events at the end of January? We

305 speculate that the extreme salinity fluctuations associated with the spring tide may have

306 stressed the barnacles and caused them to close their opercular openings. Cawthorne and

307 Davenport (1980) found that when gravid barnacles in the laboratory were exposed to

308 large and rapid salinity fluctuations, they closed their opercular openings, halting larval

309 release. Moreover, the peaks in turbidity in late January and early February occurred as

310 the tide was ebbing, so a substantial portion of the adult population may have been out of

311 the water and unable to release larvae. Finally, there is the possibility that another factor

312 not taken into account here also affects larval release.

313 To examine the relationship between phytoplankton abundance and the timing of

314 barnacle larval release, we used in vivo chlorophyll fluorescence to estimate chlorophyll-

$315 a$ concentrations, though this is known to be an imperfect method. The ratio of

316 fluorescence to chlorophyll- $a$ can vary depending on the species composition of the

317 phytoplankton, the health of the cells, and the ambient light conditions (e.g., Loftus and

318 Seliger 1975; Dandonneau and Neveaux 1997). In our data, we see decreases in

319 fluorescence almost daily during the middle of the day. This is likely due to non-

320 photochemical quenching. Non-photochemical quenching processes protect

321 phytoplankton from photooxidative damage when light energy exceeds the capability of 
322 the cell to utilize it (Müller et al. 2001). Quenching appears as a reduction in fluorescence

323 during periods of high light intensity. Thus, care must be taken in interpreting the data

324 from the brightest period of the day.

325 The results of laboratory and field experiments lend further support to the

326 hypothesis that turbidity triggers larval release. Starr et al. (1991) found that in the

327 laboratory, the larval release response is strongest when adult barnacles are fed

328 phytoplankton in concentrations 3-6 times greater than those found in typical blooms.

329 Barnacles in that study may not have been responding to the phytoplankton per se, but to

330 the mechanical stimulus from turbidity caused by high concentrations of phytoplankton

331 cells. This would explain why the barnacles did not respond to phytoplankton culture

332 filtrates, only to the presence of the cells themselves (Starr et al. 1991). The barnacles

333 also released when they were exposed to high concentrations of brine shrimp nauplii,

334 which are not a normal food item for them or their larvae in the field (Starr et al. 1991).

335 In the present study, we conducted field experiments to examine the larval release

336 response of gravid adults to Skeletonema marinoi diatoms and synthetic beads. The larval

337 release response was stronger when barnacles were exposed to the diatoms and beads

338 than when they were exposed to control conditions. The responses to diatoms and to

339 beads did not differ, suggesting that the barnacles respond to mechanical stimulation

340 from the particles, not to the identity of the particles.

341 Starr et al. (1991) suggested that particles in the water column might indicate that

342 a phytoplankton bloom is underway. Gyory and Pineda (2011) proposed that cannibalism

343 and predation may be an important source of mortality for newly-released larvae, and that

344 particles in the water column would signal turbid conditions that may provide a 
345 temporary refuge for barnacle nauplii. Semibalanus balanoides will consume its own

346 nauplii in the laboratory (Crisp and Patel 1960), and the gut contents of other barnacle

347 species sometimes contain substantial numbers of conspecific larvae (Navarrete and

348 Wieters 2000). Because suspension-feeding barnacle adults tend to be found in high

349 abundance and high densities in the intertidal zone, larvae released into this environment

350 could be at risk for cannibalism. A highly turbid environment may reduce that risk by

351 temporarily swamping the filter-feeding appendages of adults with other particles. The

352 results of our predation experiments showed that $S$. balanoides adults consumed fewer

353 nauplii in turbid conditions than in control conditions, suggesting that mortality of larvae

354 is indeed lower when turbidity is high.

355 Our study provides a new explanation for the synchrony of larval release in the

356 barnacle Semibalanus balanoides. We show that high turbidity triggers release, whether

357 the source of turbidity is a phytoplankton bloom or not. However, it is possible that

358 phytoplankton blooms also play an important role in the timing of release. The timing of

359 reproduction in this species may have evolved so that larvae are developmentally ready to

360 be released by the onset of winter/spring phytoplankton blooms in order to maximize the

361 likelihood of a plentiful food supply, and the actual timing of larval release may have

362 been fine-tuned further by cannibalism and predation pressures. As seen in our data,

363 increases in phytoplankton abundance were often very brief, so the food limitation

364 hypothesis would imply that short-lived increases in food supply have a substantial

365 benefit on the growth or survival of larvae. Turbidity increases were also very brief, but

366 the potential benefit to larval survival (reduced risk of cannibalism) would only be

367 needed for a short period until nauplii dispersed away from the adult population. Other 
368 crustaceans employ larval release strategies that reduce predation on newly-released

369 larvae (e.g., Morgan and Christy 1995). Releasing larvae during turbid conditions to

370 protect them from cannibalism or predation may be a strategy shared by other marine

371 organisms that release propagules into the water column.

372 


\section{ACKNOWLEDGEMENTS}

374

375

376 field and for help with field sampling logistics. We thank the University of Rhode Island

377 and the University of New Hampshire for access to their research facilities. We thank

378 Victoria Starczack, Carin Ashjian, Thomas Peacock, and Peter Wiebe for help with the

379 design of these experiments and for helpful comments that improved this manuscript.

380 Thanks also to the three anonymous reviewers who provided helpful feedback on an

381 earlier version of this manuscript. David Ralston and Heidi Sosik generously lent their

382 oceanographic instruments and trained JG in their use. Support for this work came from a

383 National Science Foundation Graduate Research Fellowship and a student award from

384 the Coastal Ocean Institute at Woods Hole Oceanographic Institution (both to JG). Our

385 experiments and sample collections comply with the laws and regulations of the United

386 States of America and the states of Massachusetts, Rhode Island, and New Hampshire. 


\section{LITERATURE CITED}

Barnes H (1955) The hatching process in some barnacles. Oikos 6:114-123

Barnes H (1956) Balanus balanoides (L.) in the Firth of Clyde: the developmental and annual variation of the larval population, and the causative factors. J Anim Ecol 25:72-84

Barnes H (1957) Processes of restoration and synchronization in marine ecology. The spring diatom increase and the "spawning" of the common barnacle Balanus balanoides (L.). Ann Biol 33:67-85

Barnes H (1962) Note on the variations in the release of nauplii of Balanus balanoides with special reference to the spring diatom outburst. Crustac Int J Crustac Res 4:118-122

Barnes H (1963) Light, temperature and the breeding of Balanus balanoides. J Mar Biol Assoc UK 43:717-727

Barnes H, Barnes M (1958) The rate of development of Balanus balanoides (L.) larvae. Limnol Oceanogr 3:29-32

Bousfield EL (1955) Ecological control of the occurrence of barnacles in the Miramichi estuary. Bull Natn Mus Can Biol Ser 46:1-65

Cawthorne DF, Davenport J (1980) The effects of fluctuating temperature, salinity, and aerial exposure upon larval release in Balanus balanoides and Elminius modestus. J Mar Biol Assoc UK 60:367-377

Crisp D.J, Patel BS (1960) The moulting cycle in Balanus balanoides (L.). Biol Bull 118:31-47

Dandonneau Y, Neveux J (1997) Diel variations of in vivo fluorescence in the eastern equatorial Pacific: and unvarying pattern. Deep Sea Res Part II 44:18691880

Fish CJ (1925) Seasonal distribution of the plankton of the Woods Hole region. Bull US Bur Fish 41:91-179

Foster BA (1965) Barnacle distribution in relation to behaviour, temperature and desiccation. MSc thesis, Auckland University, Auckland, New Zealand

Frolander HT (1955) The biology of the zooplankton of the Narragansett Bay area. $\mathrm{PhD}$ dissertation, Brown University, Providence, RI 
433

434

435

436

437

438

439

440

441

442

443

444

445

446

447

448

449

450

451

452

453

454

455

456

457

458

459

460

461

462

463

464

465

466

467

468

469

470

471

472

473

474

475

476

477

Gyory J, Pineda J (2011) High-frequency observations of early-stage larval abundance: do storms trigger synchronous larval release in Semibalanus balanoides? Mar Bio 158:1581-1589

Loftus ME, Seliger HH (1975) Some limitations of the in vivo fluorescence technique. Chesap Sci 16:79-92

Lockhead JH (1936) On the feeding mechanism of the nauplius of Balanus perforatus Bruguiere. Proc Limn Soc (Zool) 39:429-442

Luckens PA (1970) Breeding, settlement and survival of barnacles at artificially modified shore levels at Leigh, New Zealand. N Z J Mar Freshw Res 4:497-514

Moore HB (1935) The biology of Balanus balanoides. III. The soft parts. J Mar Biol Assoc UK 20:263-277

Morgan SG, Christy JH (1995) Adaptive significance of the timing of larval release by crabs. Am Nat 145:457-479

Müller P, Li X-P, Niyogi KK (2001) Non-photochemical quenching. A response to excess light energy. Plant Physiol 125:1558-1566

Navarrete SA, Wieters EA (2000) Variation in barnacle recruitment over small scales: larval predation by adults and maintenance of community pattern. J Exp Mar Biol Ecol 253:131-148

Pineda J, Starczak VR, DiBacco C, Genovese SJ, Richmond H (unpub.) Regional variability in larval release and settlement in the barnacle Semibalanus balanoides.

Sarno D, Kooistra WHCF, Medlin LK, Percopo I, Zingone A (2005) Diversity in the genus Skeletonema (Bacillariophyceae). II. An assessment of the taxonomy of $S$. costatum-like species with the description of four new species. J Phycol 41:151176

Starr M, Himmelman JH, Therriault J-C (1991) Coupling of nauplii release in barnacles with phytoplankton blooms: a parallel strategy to that of spawning in urchins and mussels. J Plankton Res 13:561-571

Stubbings HG (1975) Balanus balanoides. Liverpool University Press. Liverpool, England. 
478 Figure 1. Sampling sites along the northeastern coast of the United States: 1) Woods

479 Hole, Massachusetts; 2) Narragansett, Rhode Island; and 3) New Castle, New Hampshire.

480 Semibalanus balanoides release larvae sequentially, in this order, at these three sites.

482 Table 1. Number of replicates for three treatments (Skeletonema marinoi, Beads, and

483 Control) used in four experiments conducted in Rhode Island and New Hampshire.

485 Figure 2. Field surveys of the reproductive condition of adult Semibalanus balanoides

486 barnacles in Massachusetts in relation to environmental variables. (a) Percentage of adult

487 barnacles with no embryos, shown with standard error bars, suggests that there were two

488 major larval release events, indicated by grey vertical shading. (b) Percentage of adult

489 barnacles that were brooding viable larvae. (c) Chlorophyll concentration. (d) Turbidity.

490 (e) Water level relative to mean lower low water. (f) Water temperature.

491

492 Figure 3. Field surveys of the reproductive condition of adult Semibalanus balanoides

493 barnacles in Rhode Island in relation to environmental variables. (a) Percentage of adult

494 barnacles with no embryos, shown with standard error bars, suggests that there were two

495 major larval release events, indicated by grey vertical shading. (b) Percentage of adult

496 barnacles that were brooding viable larvae. (c) Chlorophyll concentration. (d) Turbidity.

497 (e) Water level relative to mean lower low water. (f) Salinity. (g) Water temperature.

499 Figure 4. Field surveys of the reproductive condition of adult Semibalanus balanoides

500 barnacles in New Hampshire in relation to environmental variables. (a) Percentage of 
501 adult barnacles with no embryos, shown with standard error bars, suggests that there was

502 one major larval release event, indicated by grey vertical shading. (b) Percentage of adult

503 barnacles that were brooding viable larvae. (c) Chlorophyll concentration. (d) Turbidity.

504 (e) Water level relative to mean lower low water. (f) Salinity. (g) Water temperature. In

505 (c), (d), (e), (f), and (g), the gray line indicates values when water level was below $1.5 \mathrm{~m}$

506 above MLLW, and the black line indicates values when it was above $1.5 \mathrm{~m}$.

507

508 Figure 5. Pooled results of the Rhode Island and New Hampshire experiments in rank

509 order. Each bar represents the number of nauplii released in each replicate jar at the end

510 of experiments in which adult barnacles were exposed to Skeletonema marinoi diatoms,

511 inert synthetic beads, or control treatment (plain filtered seawater). We rejected the null

512 hypothesis that the larval release response was the same in all three treatments $(p<<$

513 0.001). We cannot reject the null hypothesis that the larval release response was the same

514 for the $S$. marinoi and bead treatments $(p \approx 1)$.

516 Table 2. Probability, estimated by the statistical model, that an adult barnacle produced

517 nauplii for each of the four experiments conducted in Rhode Island and New Hampshire.

519 Table 3. Estimates of $\theta$ (the unknown shape parameter of the negative binomial

520 distribution) under the null hypothesis and under the three experimental treatments

521 (including and excluding an outlier), and the estimated mean number of nauplii that each 522 gravid barnacle adult released.

523 
524 Figure 6. Pooled results of the Rhode Island and New Hampshire experiments in rank

525 order. Each bar represents the percentage of adult barnacles that had not released larvae

526 by the end of the experiment within a replicate jar. Replicate jars that had fewer than five

527 percent of adults brooding larvae at the end of the experiment were considered to have

528 undergone "mass release.” Twenty-seven percent of replicates for the control treatment

529 had mass release. In contrast, forty-six percent and fifty-four percent of bead and diatom

530 replicates, respectively, had mass release.

532 Figure 7. Results of experiments in which adult barnacles were exposed to newly-

533 released nauplii under high-turbidity (Experimental) or low-turbidity (Control) conditions.

534 Predation rates by adult barnacles on nauplii were lower in high-turbidity than in low-

535 turbidity conditions (ANOVA, $p=0.015$ ). Triangles represent the means, boxes represent

536 the median and standard error of the mean. Whiskers represent the minimum and

537 maximum values. On average, $85.4 \%$ of nauplii in the turbidity treatment escaped

538 predation, compared to $64.7 \%$ in the control treatment. 
Turbidity triggers larval release

549

550

551

552

553

554

555

556

557

558

559

560

561

562

563

564

565

566

567

568

569

570

571

572

573

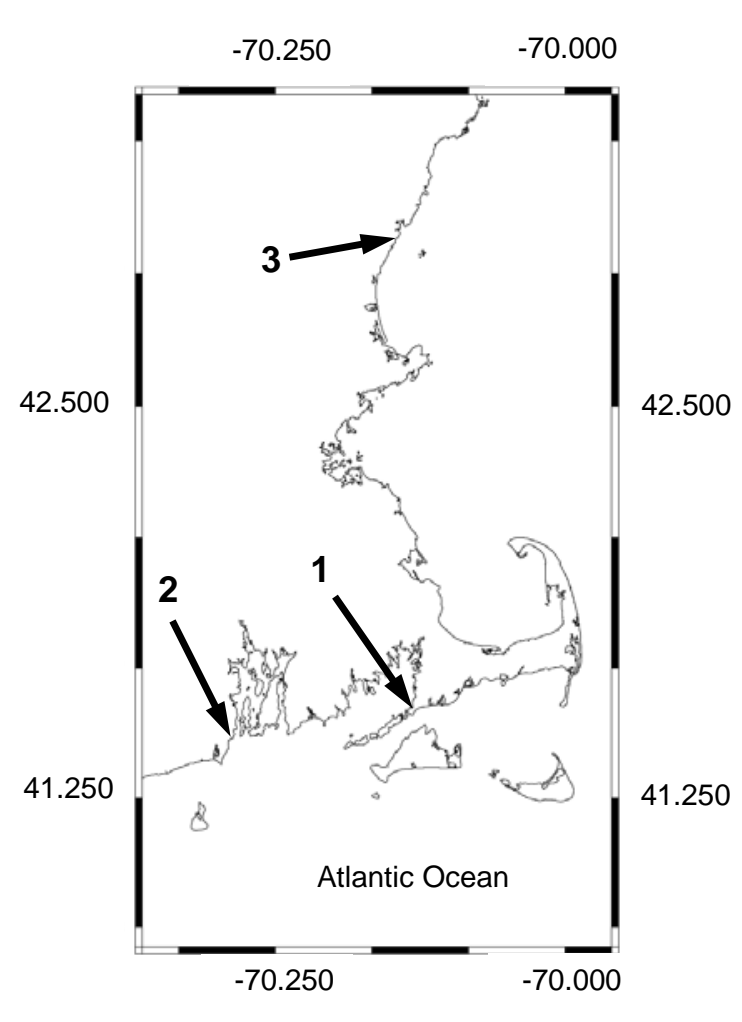

Figure 1 
574

\begin{tabular}{ccccc} 
& $\begin{array}{c}\text { Rhode } \\
\text { Island }\end{array}$ & $\begin{array}{c}\text { Rhode } \\
\text { Island }\end{array}$ & $\begin{array}{c}\text { New } \\
\text { Hampshire }\end{array}$ & $\begin{array}{c}\text { New } \\
\text { Hampshire }\end{array}$ \\
\cline { 2 - 5 } & Jan 11 2010 & Jan 13 2010 & Jan 31 2010 & Feb 02 2010 \\
\cline { 2 - 5 } Skeletonema & 4 & 3 & 5 & 5 \\
Beads & 4 & 3 & 5 & 5 \\
Control & 2 & 1 & 5 & 5
\end{tabular}

575

576 Table 1

577

578 


\begin{tabular}{|c|c|c|c|c|}
\hline & $\begin{array}{l}\text { Rhode } \\
\text { Island }\end{array}$ & $\begin{array}{l}\text { Rhode } \\
\text { Island }\end{array}$ & $\begin{array}{c}\text { New } \\
\text { Hampshire }\end{array}$ & $\begin{array}{c}\text { New } \\
\text { Hampshire }\end{array}$ \\
\hline & Jan 112010 & Jan 132010 & Jan 312010 & Feb 022010 \\
\hline $\begin{array}{c}\text { Probability } \\
\text { under } H_{0}\end{array}$ & $31.0 \%$ & $3.2 \%$ & $3.0 \%$ & $4.1 \%$ \\
\hline $\begin{array}{c}\text { Probability } \\
\text { under } H_{1}\end{array}$ & $24.0 \%$ & $4.5 \%$ & $3.0 \%$ & $4.7 \%$ \\
\hline $\begin{array}{c}\text { Probability } \\
\text { under } H_{1} \text { with } \\
\text { outlier removed }\end{array}$ & $18.0 \%$ & $5.0 \%$ & $3.0 \%$ & $5.0 \%$ \\
\hline
\end{tabular}

\section{Table 2}

582 
Turbidity triggers larval release

583

\begin{tabular}{ccccc} 
& Under $H_{0}$ & $\begin{array}{c}\text { Under } H_{1} \\
\text { Control }\end{array}$ & $\begin{array}{c}\text { Under } H_{1} \\
\text { Beads }\end{array}$ & $\begin{array}{c}\text { Under } H_{1} \\
\text { Diatoms }\end{array}$ \\
\cline { 2 - 5 } Estimate of $\theta$ & 0.0018 & 0.038 & 0.005 & 0.001 \\
$\begin{array}{c}\text { Estimate of } \theta \\
\text { with outlier removed }\end{array}$ & 0.006 & 0.042 & 0.0049 & 0.0051 \\
$\begin{array}{c}\text { Estimated mean } \\
\text { number of nauplii } \\
\text { released per gravid } \\
\text { adult }\end{array}$ & 165.67 & 22.81 & 203.08 & 195.08 \\
& & & & \\
& & & &
\end{tabular}

585 Table 3

586 


\section{Massachusetts}

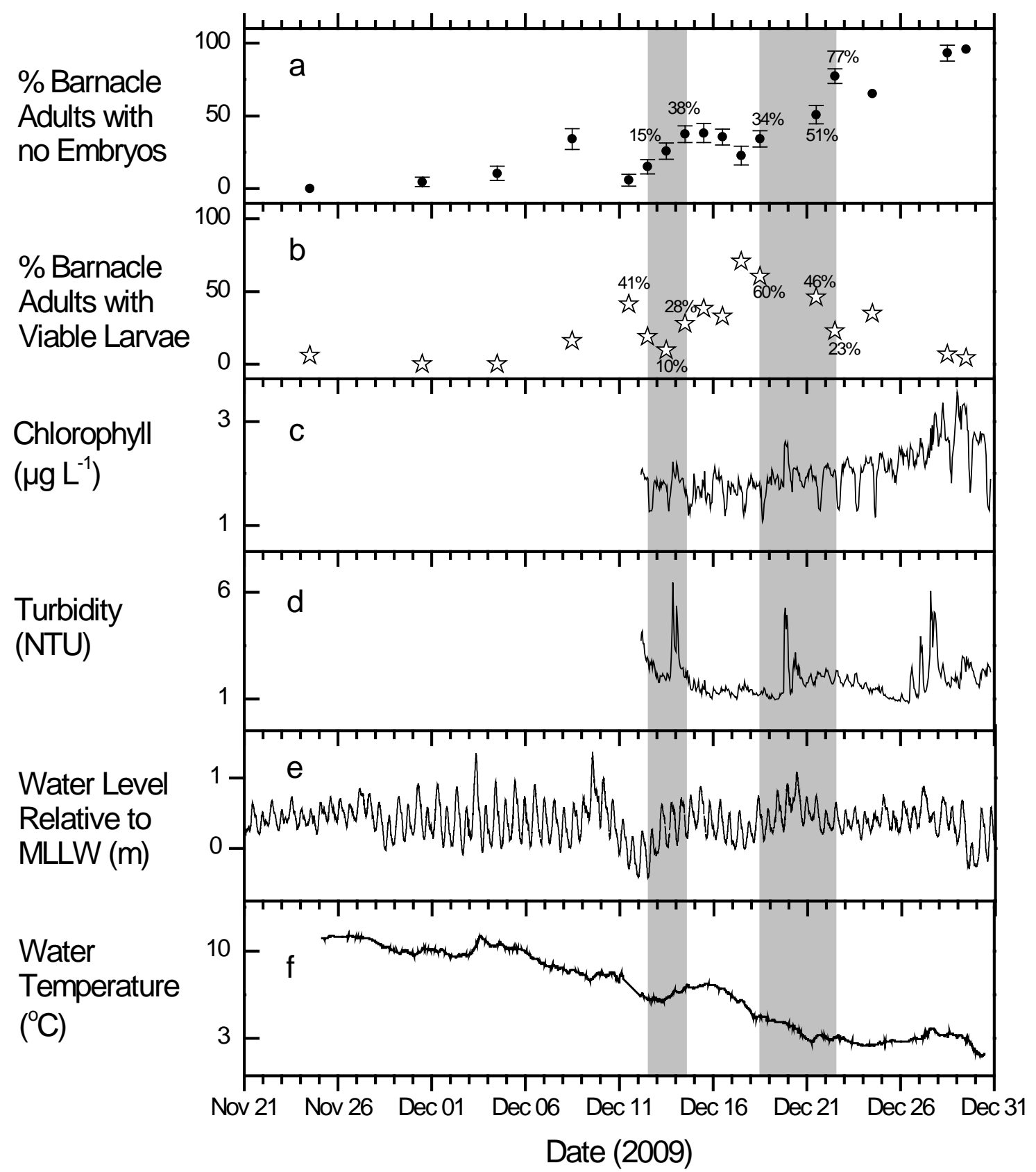

Figure 2 


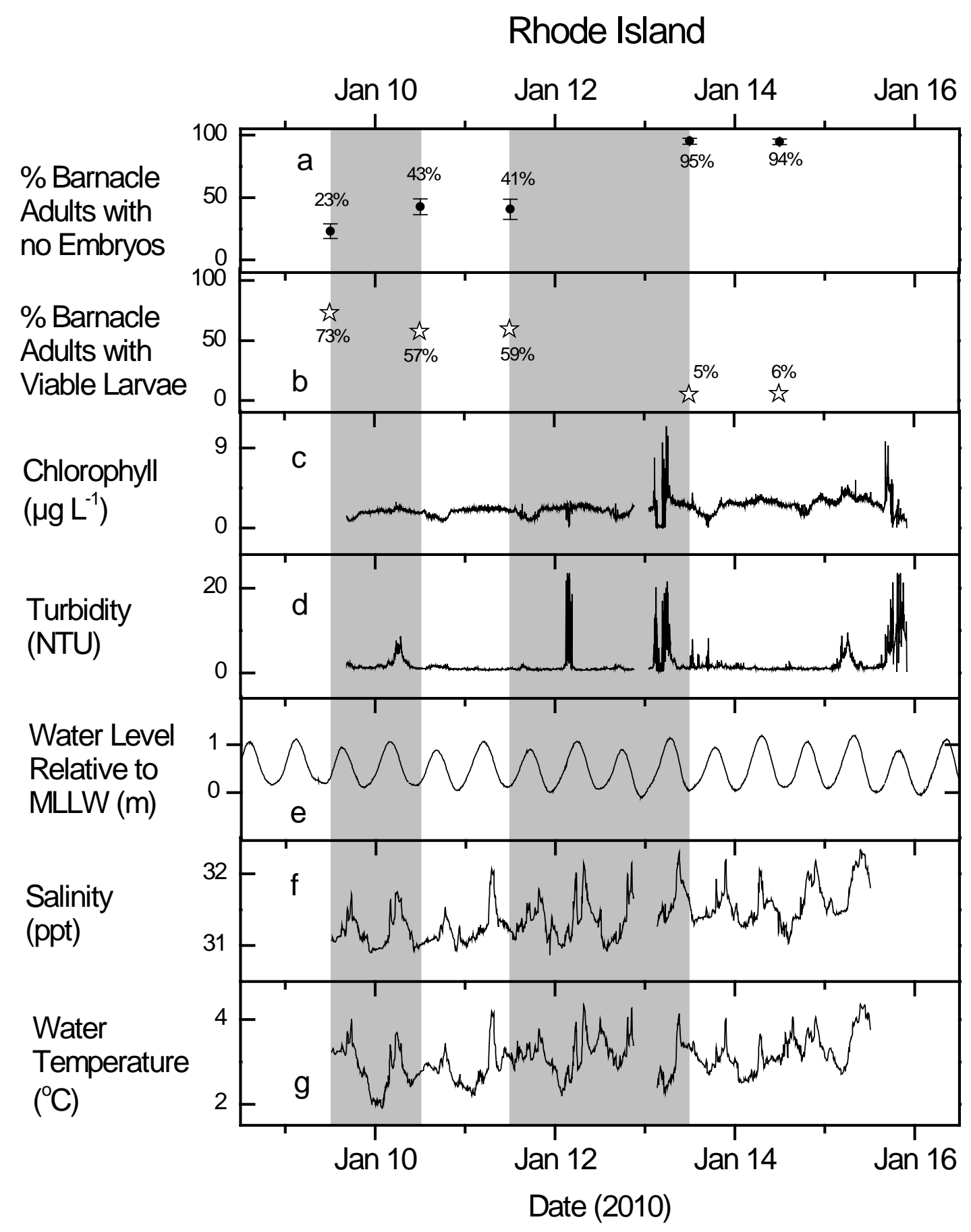

Figure 3 
New Hampshire

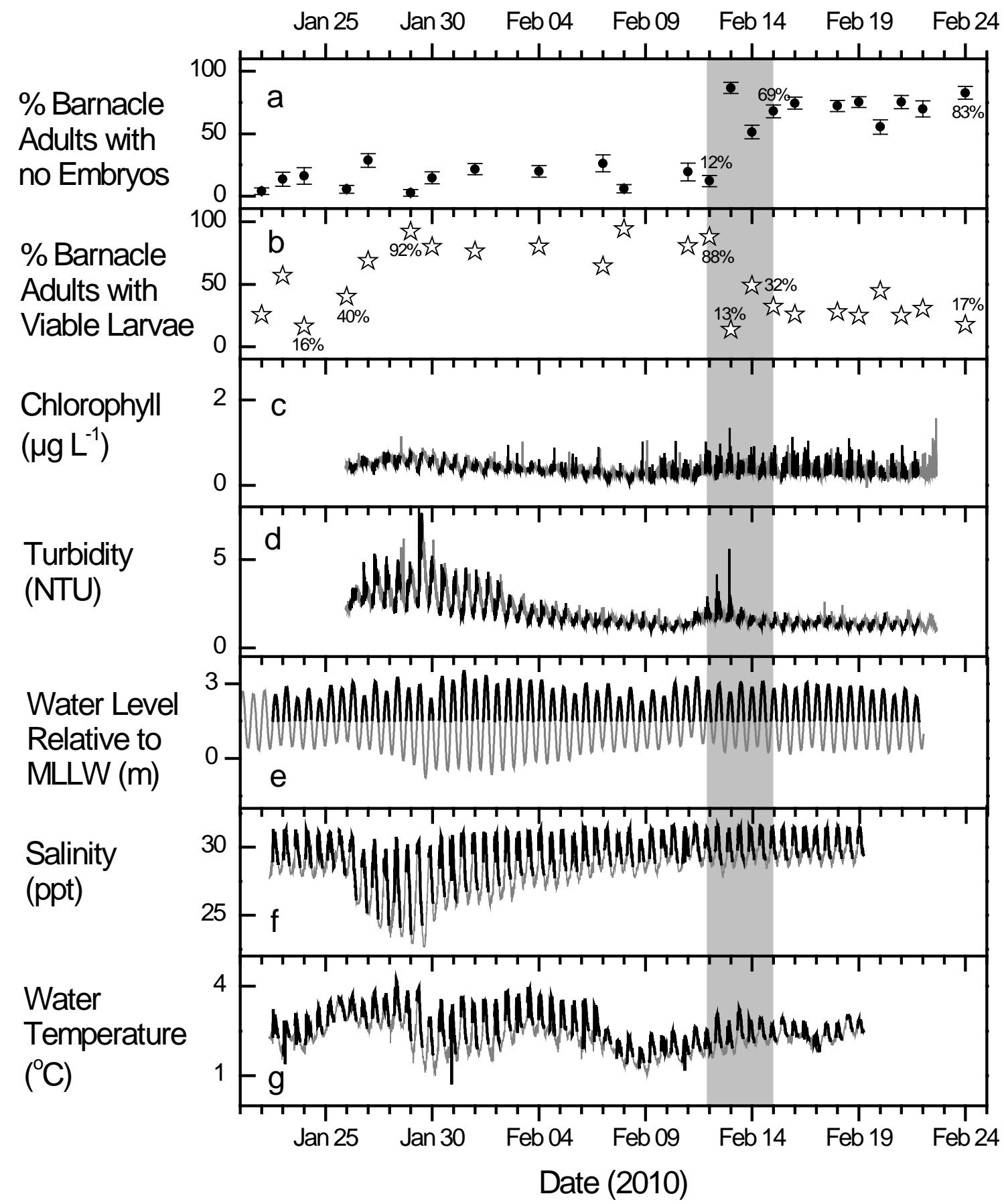

Figure 4 
Turbidity triggers larval release

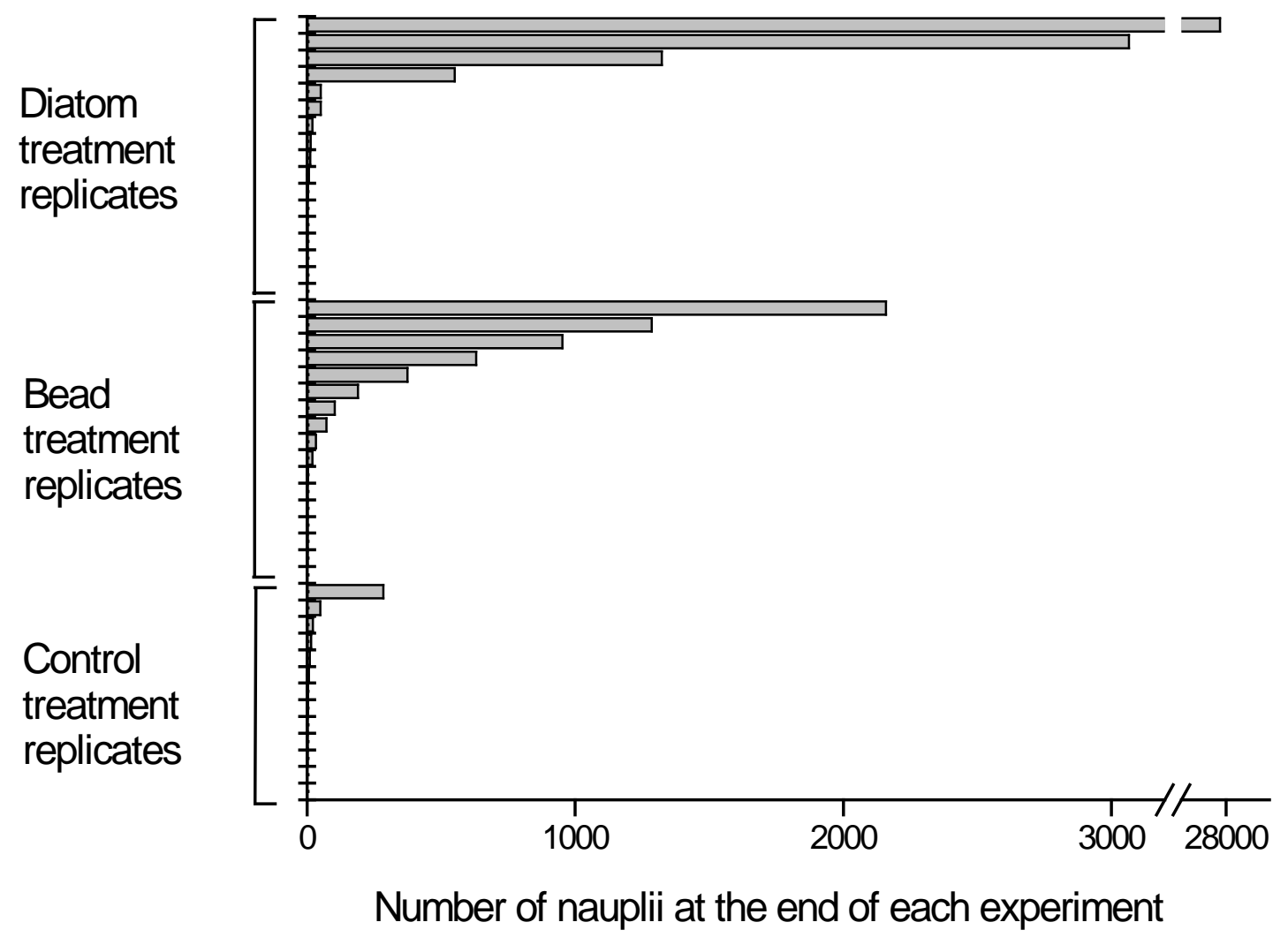

599

600

$601 \quad$ Figure 5

602

603 


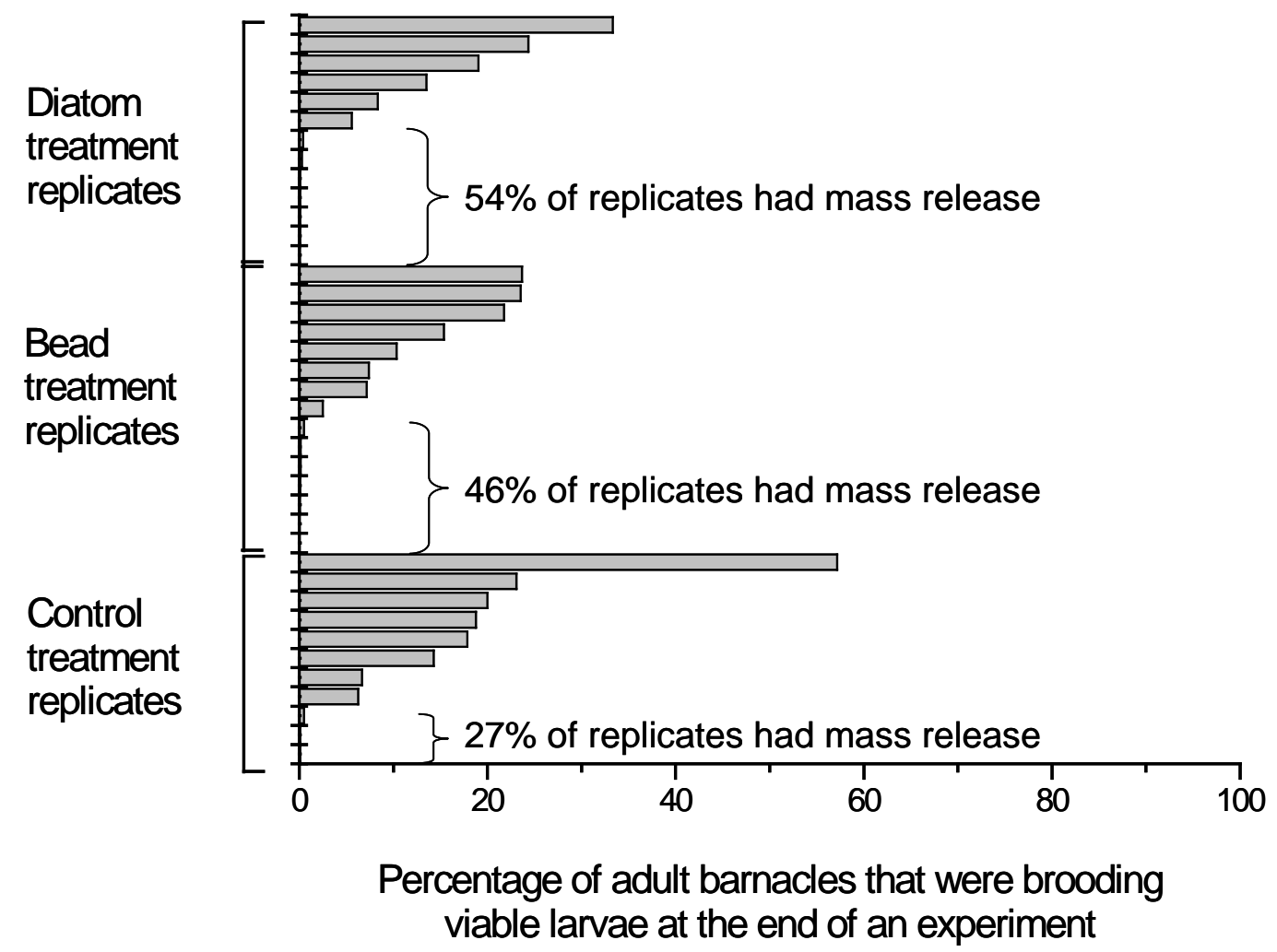

Figure 6

607

608

609

610

611 
Turbidity triggers larval release

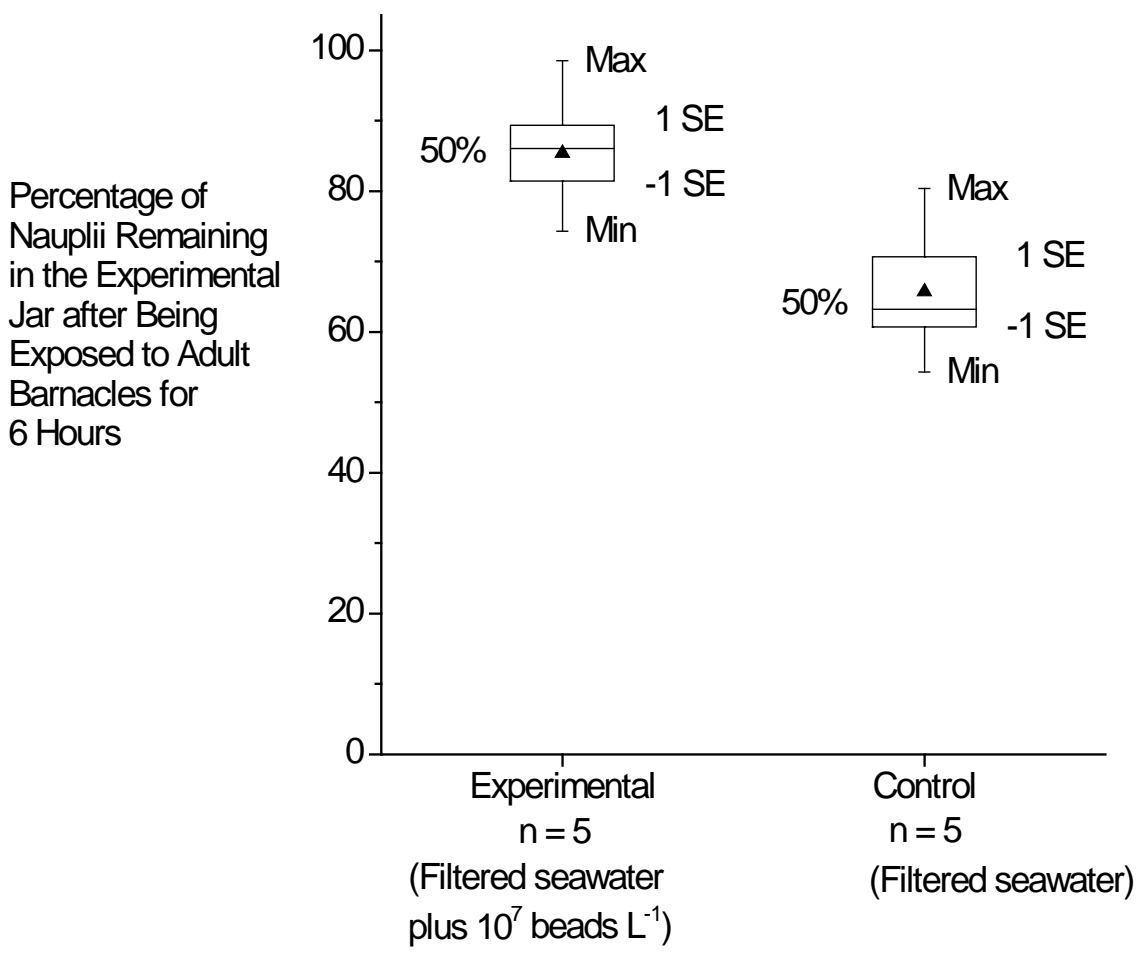

612

613

$614 \quad$ Figure 7

615 


\section{Electronic Supplement 1}

\section{Data filtering method for the Massachusetts site}

The chlorophyll and turbidity raw data in Little Harbor, Massachusetts exhibited some unrealistically high values, probably caused by a piece of macroalga that wrapped itself around the instrument. Since the instrument sampled at a high frequency and not all of the data seemed to be contaminated, we devised an ad-hoc method for filtering out bad data. It proceeded in three steps:

1. The instrument sampled once per second for 5 seconds every 5 minutes, so we computed the median for each of the 5-second sampling bursts. This eliminated bad data in situations when only some of the values in the sampling burst were contaminated (Fig 1b, 2b).

2. To remove bad data in instances when the entire sampling burst was contaminated, we divided the sampling period into 2-hour bins, and we filtered the data in each bin as follows: we calculated the mean and standard deviation of the values in the 2-hour bin. If the standard deviation of the mean was equal to or greater than half of the mean, then we eliminated the highest $1 / 3$ of values from the 2-hour bin (Fig 1c, 2c).

3. Finally, we calculated the median values for each 1-hour bin, and those are the values that we used in our analyses (Fig 1d, 2d, Fig 3). 
639

640

641

649

650

651

652

653

654

655

656

664

665

666

667

668

669

670

671

672

673

674

675

676

677

678

679

680

681

682

683

684
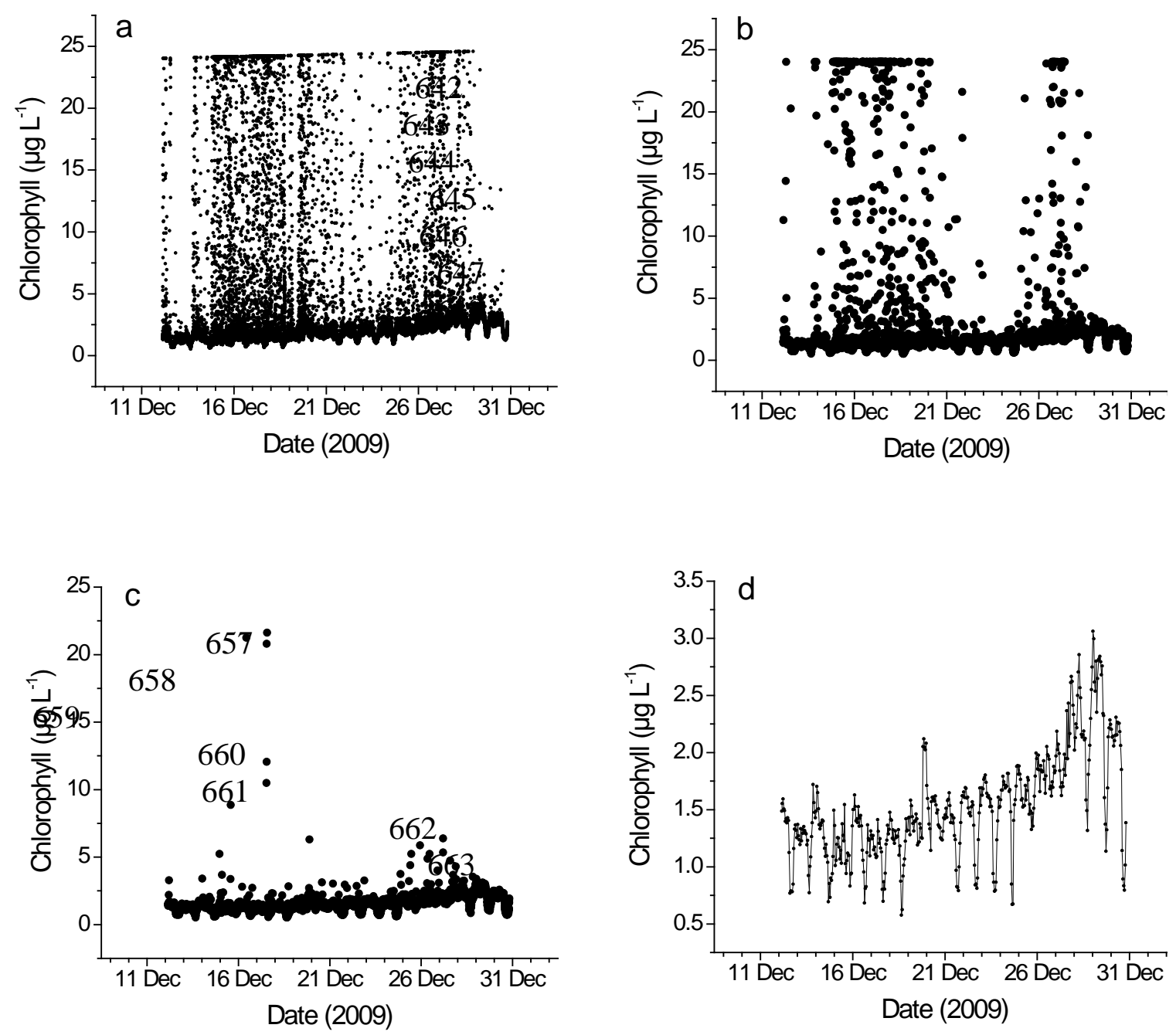

Figure 1. The process of data filtration for chlorophyll measurements from Little Harbor, Massachusetts. (a) Raw chlorophyll data (b) Median values for each 5-second sampling burst (c) Results of filtering data in 2-hour bins. (d) Median values for each 1-hour bin. Note that the y-axis scale differs from the other three plots. 
685

686

687

688

689

690

698

699

700

701

702

703

704

705

706

707

708

715

716

717

718

719

720

721

722

723

724

725

726

727

728

729

730

731
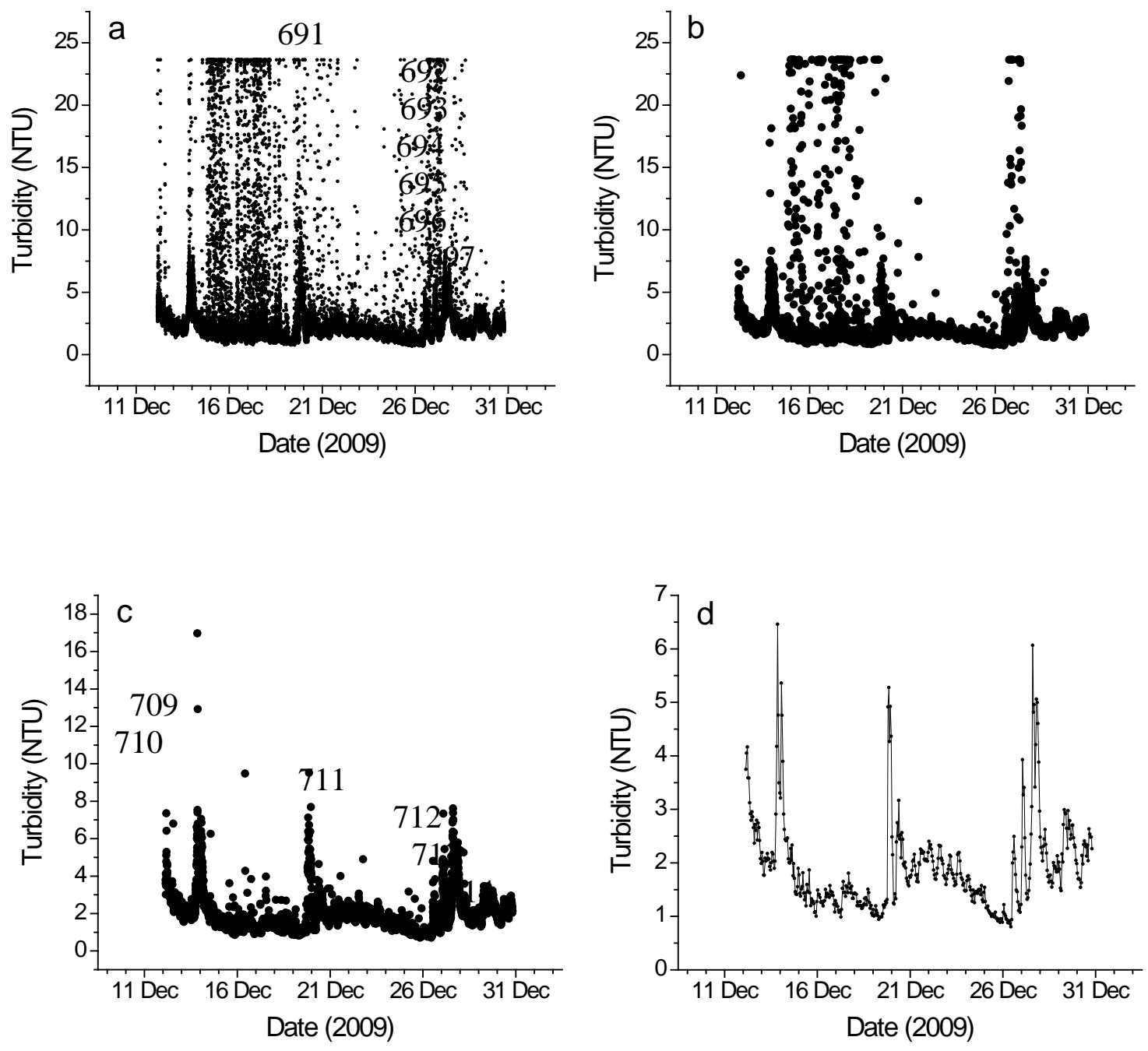

Figure 2. The process of data filtration for turbidity measurements from Little Harbor, Massachusetts. (a) Raw turbidity data (b) Median values for each 5-second sampling burst (c) Results of filtering data in 2-hour bins. (d) Median values for each 1-hour bin. Note that the y-axis scale differs among plots. 
Turbidity triggers larval release

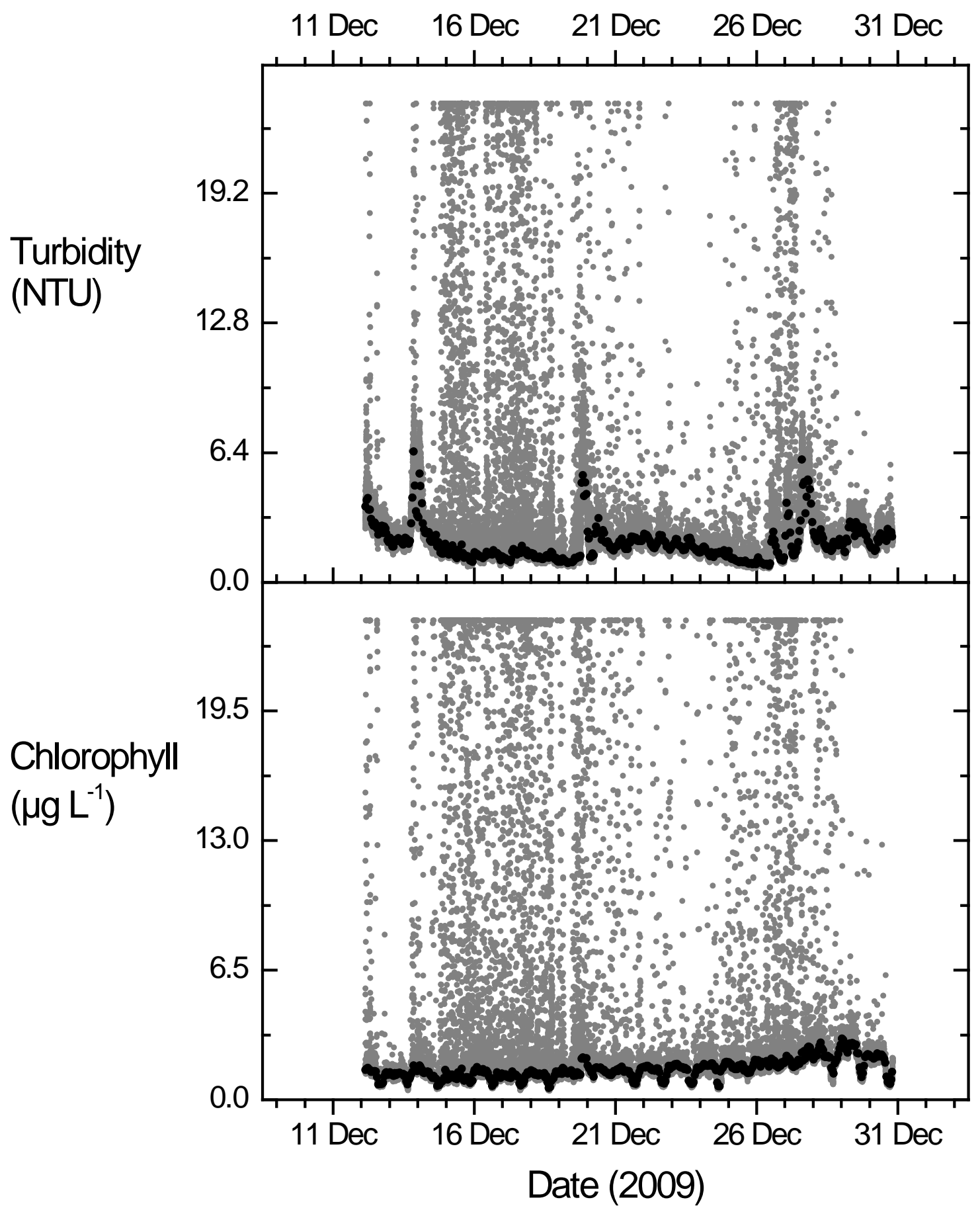

Figure 3. Raw turbidity and chlorophyll data are shown in gray dots. The black dots 


\section{Electronic Supplement 2}

741 Statistical model for testing the hypothesis that there is a difference in the larval release response of adult barnacles when exposed to one of three treatments

745 barnacle adults and let $y$ be the observed number of nauplii in the jar at the end of the

746 experiment. An adult is not necessarily capable of producing nauplii, either because it

747 had released the larvae prior to the start of the experiment, or because it does not respond

748 to the experimental treatment. Let $\pi$ be the unknown probability that an adult is gravid

749 and receptive to the larval release cue being tested. We allow $\pi$ to be different for each of

750 the four experiments we conducted.

751 Under the model, the unknown number $N$ of adults capable of producing nauplii

752 has a binomial distribution with probability mass function given by:

753

754

$$
p(n)=\left(\begin{array}{l}
m \\
n
\end{array}\right) \pi^{n}(1-\pi)^{m-n}
$$

756 where $n$ is the number of adults that release larvae.

757 Conditional on its being gravid and receptive to the larval release cue, we

758 assumed that the number $x$ of nauplii produced by a single adult follows a geometric

759 distribution with probability mass function:

760

$$
p(x)=\theta(1-\theta)^{x} \quad x=0,1,2, \ldots
$$


763 with unknown parameter $\theta(0<\theta<1)$. The geometric distribution is commonly used as a

764 model for count data with a long upper tail. The mean and variance of $x$ are $(1-\theta) / \theta$ and $765(1-\theta) / \theta^{2}$, respectively.

766 The total number $y$ of nauplii observed inside a jar at the end of an experiment

767 represents the sum of a random number $N$ of independent and identically distributed

768 geometric counts. The probability mass function of $y$ is given by:

$$
p(y)=\sum_{n=0}^{m} p(y \mid n) p(n)
$$

772 where $p(y \mid n)$ is the conditional probability mass function of $y$ given $N=n$, which can be

773 shown to be negative binomial with scale parameter $n$ and shape parameter $\theta$. The

774 negative binomial probabilities required for the calculation of (3) were approximated by

775 the method of Best \& Gipps (1974).

776 The analysis proceeded using the basic model outlined above, allowing $\pi$ to vary

777 among the 4 experiments and with interest centering on testing the null hypothesis $H_{0}$ that

778 the geometric parameter $p$ is the same for the three treatments (control, synthetic beads,

779 and Skeletonema marinoi diatoms) against the alternative hypothesis $H_{1}$ that it is not. We

780 used the likelihood ratio (LR) test, which involved fitting the model under both $H_{0}$ and $H_{1}$.

781 The LR test statistic is given by:

782

783

$$
\Lambda=2\left[\log \mathrm{L}_{1}-\log \mathrm{L}_{0}\right]
$$


785 where $\mathrm{L}_{1}$ is the maximized likelihood value under $H_{1}$ and $\mathrm{L}_{0}$ is the maximized likelihood

786 value under $H_{0}$. Under $H_{0}, \Lambda$ has an approximate chi-squared distribution with degrees of

787 freedom given by the difference in the number of parameters under $H_{1}$ and $H_{0}$. In this

788 case, there are 7 parameters under $H_{1}$ (one geometric parameter for each treatment and

789 one binomial probability for each of the four experiments), and 5 under $H_{0}$ (one common

790 geometric parameter and one binomial probability for each treatment). Thus, there are

791 two degrees of freedom.

792 We repeated the entire analysis but omitted the outlier from the Skeletonema

793 treatment, as this has undue influence on the results. We also used the LR test to test the

794 null hypothesis that the geometric parameter is the same for the bead treatment and the

795 Skeletonema treatment.

796

797

798

799

800 Summary of variables involved in the statistical analysis of experimental data:

\begin{tabular}{|l|l|}
\hline$m$ & number of adult barnacles in a jar \\
\hline$n$ & number of adults that release larvae \\
\hline$\pi$ & unknown probability that an adult is gravid and receptive to a larval release cue \\
\hline$N$ & the unknown number of adults that are gravid and receptive to a larval release cue \\
\hline$X$ & number of nauplii produced by a single adult \\
\hline$\theta$ & unknown shape parameter of the negative binomial distribution \\
\hline$y$ & total number of nauplii inside a jar at the end of an experiment \\
\hline$\Lambda$ & test statistic of the likelihood ratio test \\
\hline
\end{tabular}

801

\section{$802 \quad$ Literature Cited}

803 Best DJ, Gipps PG (1974) An improved gamma approximation to the negative binomial. 804 Technometrics 16: 621-624 